\title{
EFEITOS DA ESPLENECTOMIA NA PERITONITE CAUSADA POR LESÃO TRAUMÁTICA DO CÓLON: ESTUDO EM RATOS
}

Luís Sérgio Nassif*, João Carlos Domingues Repka, Ana Cláudia Thá Nassif, Alcides José Branco Filho, Márcia Olandoski

Trabalho realizado na Pontifícia Universidade Católica do Paraná - PUC, Curitiba, PR.

RESUMO - OBjETIVo. Estudar o efeito da esplenectomia na infecção intra-abdominal com bactérias da flora enteral, liberadas para a cavidade abdominal através de uma lesão induzida no cólon de ratos Wistar.

Métodos. Foram utilizados 64 animais, sendo 20 do Grupo $A_{1}$ (normais sem sutura da lesão), 22 do Grupo $A_{2}$ (normais com sutura da lesão) e 22 do Grupo B (esplenectomizados e com sutura da lesão). Os animais foram submetidos à laparotomia mediana e a indução da peritonite intra-operatória foi obtida através de lesão do cólon previamente distendido pela introdução de uma sonda naso-gástrica via retal e injeção de $2 \mathrm{ml}$ de soro fisiológico. Foram realizados exames bacteriológicos de lavado abdominal obtido por swab esterelizado e exame microscópico de segmento suturado do cólon de amostras obtidas dos grupos $A_{2}$ e $B$ com $48 \mathrm{hs}, 96 \mathrm{hs}$ e 12 dias de pósoperatório. Todos os animais foram submetidos a necropsia por ocasião do óbito ou no $12^{\circ}$. dia de pós-operatório quando os sobreviventes foram sacrificados.

Resultados. Agentes bacterianos semelhantes foram encontrados nos três grupos: E.coli (100\%); Enterococcus faecalis (97\%); P. mirabilis $(90 \%)$; Klebsiela pneumoniae $(70 \%)$; Citobacter freundi (70\%) e Enterobacter aglomerans (63\%). 0 exame microscópico revelou menor reação inflamatória no grupo esplenectomizado. A causa da morte na maioria foi peritonite nas primeiras $96 \mathrm{hs}$. Houve alto índice de significância de mortalidade entre os animais do Grupo B (80\%) em relação ao Grupo $A_{2}$ (sem mortalidade) e em relação ao Grupo $A_{1}$ (35\%).

Conclusão. Houve alto índice de significância de mortalidade em vigência de peritonite nos animais esplenectomizados em relação aos animais que não foram esplenectomizados.

Unitermos: Esplenectomia. Cólon. Peritonite. Mortalidade.

\section{INTRODUÇÃO}

Muito se tem relatado a respeito da atuação do baço na defesa do hospedeiro. O baço, juntamente com os linfonodos, são os principais locais para a iniciação de grande parte da resposta imune primária e para a ativação de linfócitos B com conseqüente produção de anticorpos'. A função fagocitária do baço, facilitada pela filtração lenta do sangue através dos cordões esplênicos permitindo contato das células fagocitárias com as partículas e bactérias, tem sido estudada por vários autores que demonstraram o papel do clareamento exercido por este órgão, principalmente na ausência de anticorpo específico². O baço é o maior responsável pela produção de Tuftsin, uma gamaglobulina que exerce importante papel estimulador da atividade dos neutrófilos ${ }^{3}$. Além disso, importantes opsoninas são sintetizadas no baço e a ausência deste diminui a

*Correspondência:

Rua Imaculada Conceição, 1155 - Prado Velho CEP: 80215-901 - Curitiba - Paraná opsonização, dificultando a fagocitose ${ }^{2}$. Observou-se que, após o quinto dia da esplenectomia, ocorre uma leucocitose fisiológica e que uma relação entre plaquetas/leucócitos menor que 20 está altamente associada à septicimia ${ }^{4}$. Wolf et al $\left(\right.$ (999) ${ }^{5}$ constataram uma diminuição de linfócitos $T$ bem como de CD4 e CD45RO em pacientes submetidos à esplenectomia por trauma, fato que sugere um importante papel do baço na geração, manutenção e diferenciação dos linfócitos T e seus precursores. Durante as duas últimas décadas, várias publicações revelaram resultados que indicam altos índices de complicações infecciosas precoces ou tardias, bem como índices importantes de óbitos decorrentes das alterações determinadas pela ausência do baço. Apesar de existirem trabalhos que correlacionam infecção ao estado asplênico e suas complicações, existem poucos estudos prospectivos comparando a infecção em pacientes que foram submetidos à esplenectomia e em indivíduos com baço preservado ${ }^{6}$.

Este estudo teve por objetivo avaliar a in fluência da esplenectomia na morbimortalidade de ratos Wistar, acompanhando a evolução da infecção intra-abdominal com bactérias da flora enteral liberadas para a cavidade abdominal através de uma lesão induzida no cólon.

\section{Métodos}

Foram utilizados 64 ratos da raça Wistar com idade e peso homogêneos, assim distribuídos: 20 ratos sem sutura de lesão induzida no colon (Grupo $A_{1}$ ), 22 ratos com sutura de lesão (Grupo $A_{2}$ ) e 22 ratos com esplenectomia + sutura (Grupo B).

Após indução anestésica via intra-peritoneal de soluçãa a 10\% de Hidrato de Cloral, foi feita abertura abdominal de $5 \mathrm{~cm}$. A indução da peritonite intra-operatória foi obtida através de lesão do cólon, o qual foi previamente distendido pela introdução de uma sonda naso gástrica SNG n- I2, marcada a $5 \mathrm{~cm}$ da extremidade distal e introduzida via retal e injeção de $2 \mathrm{ml}$ de soro fisiológico. A lesão do cólon foi feita a tesoura com $0,5 \mathrm{~cm}$ no sentido transversal, a $5 \mathrm{~cm}$ da borda anal. Tal procedimento propiciou grande contaminação da cavidade 
abdominal. Nos animais do Grupo A, não foi feita a sutura da ferida do cólon e nos animais dos Grupos A e B, a rafia do cólon foi feita em plano único (total) através de três pontos separados com polidactina. Os animais do Grupo B foram submetidos à esplenectomia antes da lesão do cólon. Para tanto, o baço foi luxado da cavidade abdominal e os vasos da arcada esplênica foram pinçados e seccionados em três segmentos e, em seguida, feita a ligadura. Em todos os animais, o fechamento da parede abdominal foi feito em dois planos sendo usado fio de polidactina em sutura contínua.

No momento da indução da lesão colônica, foram coletadas amostras do lavado colônico (por swab esterelizado) para exames bacteriológicos. Do segmento suturado de cólon foram obtidas amostras de material para exames histopatológicos após 48 horas, 96 horas e 12 dias do procedimento cirúrgico. Por ocasião do óbito espontâneo ou sacrifício no $12^{\circ}$. dia de pós-operatório, foi feita necropsia de exame macroscópico dos órgãos das cavidades abdominal e torácica.

Para a análise estatística foi utilizado o software Epi-Info. Os resultados foram apresentados em freqüências e percentuais e o nível de significância adotado foi de 5\%. Diferenças entre os grupos foram avaliadas pelos testes exato de Fisher ou de Qui-quadrado com correção de Yates, quando apropriados.

O trabalho teve seu projeto previamente aprovado pela Comissão de Ética em Pesquisa do Centro de Ciências e Biológicas e da Saúde da PUC-PR

\section{Resultados}

Os resultados dos exames bacteriológicos revelaram que os agentes bacterianos liberados na cavidade abdominal por ocasião da ferida no cólon foram diversificados e intensos quando isolados (Tabela I). Não foram encontradas diferenças significativas entre os grupos.

A análise microscópica de segmentos do cólon realizada evidenciou que, com 48 horas de pós-operatório, havia edema discreto na sub-mucosa do Grupo B e acentuado na sub-mucosa do Grupo $A_{2}$. Após 96 horas de evolução, no Grupo B isto praticamente não existiu e no Grupo $A_{2}$ ainda foi observado, porém de forma discreta. A serosa apre sentou, com 48 horas de evolução, densa exudação neutrofilica no Grupo $A_{2}$ e, no

\begin{tabular}{|c|c|c|c|c|}
\hline $\begin{array}{l}\text { Espécies bacterianas } \\
\text { isoladas }\end{array}$ & $\begin{array}{c}\text { Grupo } A_{1} \\
\text { (normal } \\
\text { sem sutura) }\end{array}$ & $\begin{array}{c}\text { Grupo } A_{2} \\
\text { (normal } \\
\text { com sutura) }\end{array}$ & $\begin{array}{c}\text { Grupo B } \\
\text { (esplenectomizados) }\end{array}$ & $\begin{array}{l}\text { Valor } \\
\text { dep* }\end{array}$ \\
\hline Escherichia coli & $100 \%$ & $100 \%$ & $100 \%$ & ns \\
\hline Enterococcus faecalis & $100 \%$ & $90 \%$ & $100 \%$ & ns \\
\hline Proteus mirabilis & $90 \%$ & $90 \%$ & $90 \%$ & ns \\
\hline Citrobacter freundii & $70 \%$ & $70 \%$ & $70 \%$ & ns \\
\hline Enterobacter aglomerans & $60 \%$ & $70 \%$ & $60 \%$ & ns \\
\hline Klebsiella pneumoniae & $70 \%$ & $70 \%$ & - & - \\
\hline Klebsiella oxytoca & $70 \%$ & - & $70 \%$ & - \\
\hline
\end{tabular}

(*) Teste de qui quadrado

\begin{tabular}{|c|c|c|c|c|c|}
\hline \multicolumn{6}{|c|}{ Tabela 2 - Resultados da análise macroscópica } \\
\hline \multirow{2}{*}{ Variáveis } & \multirow{2}{*}{$\begin{array}{c}\text { Grupo } \\
\mathbf{A}_{1} \\
\end{array}$} & \multirow{2}{*}{$\begin{array}{c}\text { Grupo } \\
\mathrm{A}_{2} \\
\end{array}$} & \multirow{2}{*}{$\begin{array}{c}\text { Grupo } \\
\text { B }\end{array}$} & \multicolumn{2}{|c|}{ Valor de $p$} \\
\hline & & & & Grupo $A_{1} \times$ Grupo $A_{2}$ & Grupo $A_{2} \times$ Grupo B \\
\hline $\begin{array}{l}\text { Óbito } \\
\text { Distensão abdominal } \\
\text { Abscesso na parede } \\
\text { Abscesso intra-abdominal } \\
\text { Líquido na cavidade abdominal } \\
\text { Peritonite difusa } \\
\text { Distensão de alcas } \\
\text { Alteraçõos no tórax }\end{array}$ & $\begin{array}{l}35 \% \\
35 \% \\
25 \% \\
45 \% \\
35 \% \\
35 \% \\
35 \% \\
15 \% \\
\end{array}$ & $\begin{array}{l}0 \% \\
0 \% \\
20 \% \\
25 \% \\
10 \% \\
0 \% \\
5 \% \\
0 \%\end{array}$ & $\begin{array}{l}80 \% \\
80 \% \\
10 \% \\
15 \% \\
80 \% \\
80 \% \\
80 \% \\
10 \%\end{array}$ & $\begin{array}{l}0,0042^{*} \\
0,0042^{*} \\
n s^{*} \\
n s^{2} \\
n s^{*} \\
0,0042^{*} \\
0,0218^{*} \\
n s^{*}\end{array}$ & $\begin{array}{l}<0,\left.000\right|^{2} \\
<0,\left.000\right|^{2} \\
n s^{*} \\
n s^{*} \\
<0,\left.000\right|^{2} \\
<0,\left.000\right|^{2} \\
<0,\left.000\right|^{2} \\
n^{*}\end{array}$ \\
\hline
\end{tabular}

Grupo $A_{1}$ : normal sem sutura; Grupo $A_{2}$ : normal com sutura; Grupo B: esplenectomizados

(*) Teste exato de Fisher

(2) Teste de qui quadrado

Grupo B, foi encontrada moderada quantidade de polimorfonucleares. Após 96 horas, a serosa ainda apresentava edema e exudação neutrofilica no Grupo $A_{2}$, enquanto que no Grupo B foram evidenciados poucos macrófagos e moderada quantidade de polimorfonucleares, linfócitos e plasmócitos. A mucosa, em todas as avaliações, apresentava-se întegra em ambos os grupos. Na fase tardia, com 12 dias de pós-operatório, no Grupo $\mathrm{A}_{2}$ foram encontrados macrófagos que se estendiam a toda espessura da parede do cólon e, no Grupo B, estes não foram visualizados. Ainda neste grupo, havia ulcerações da mucosa que se estendiam até a serosa, enquanto que no Grupo $A_{2}$ as ulcerações existentes não eram tão profundas e havia presença de reepitelização. Neste momento do experimento, não foram encontradas outras diferenças no padrão microscópico dos dois grupos avaliados. Em ambos, foram observados fibrose, infiltrado de linfócitos, plasmócitos, macrófagos e polimorfunucleares que se estendem a toda espessura da parede e hiperplasia linfóide na sub-mucosa.
$\mathrm{Na}$ análise macroscópica dos animais, as variáveis observadas foram óbito, presença de distensão abdominal, abscesso na parede, abscesso intra-abdominal, líquido na cavidade abdominal, peritonite difusa, distensão de alças e alterações no tórax. Os resultados descritivos e das comparações entre os grupos são apresentados na Tabela 2.

A causa da morte dos animais do Grupo B foi, para a maioria, a peritonite difusa já nas primeiras 96 horas de pós-operatório, sendo que não foram observadas deiscências das suturas do cólon nestes animais. Quando comparada a viabilidade dos animais nos Grupos A e $B$, os resultados demonstraram diferença significativa na mortalidade $(p=0,0 \mid 05)$. Não houve diferença no índice de deiscência de sutura entre os grupos estudados, sendo encontrado apenas 4,7\% de deiscência entre os animais. Evidenciou-se, ainda, a grande capacidade de bloqueio da ferida do cólon, principalmente pela bexiga, vesícula seminal e intestino delgado. Nos Grupos A, e $A_{2}$, nos quais houve maior número de sobreviventes, observou-se incidência de $50 \%$ e $40 \%$ de abscessos, 
respectivamente. Já no Grupo B, foram encontrados apenas dois animais com abscessos, pois o alto índice de mortalidade nas primeiras 96 horas não permitiu a formação de processos supurativos.

Em relação à mortalidade, no Grupo $A$, foram observados sete óbitos, sendo dois em 24 horas, três em 48 horas, um no $7^{\circ}$. dia e um no $10^{\circ}$. dia. No Grupo B, ocorreram 16 óbitos, sendo um em 36 horas, três em 48 horas, seis em 72 horas, quatro em 96 horas, um no $6^{\circ}$. dia e um no $8^{\circ}$. dia.

\section{Discussão}

Na literatura encontra-se grande número de publicações sobre a função imunológica e hematológica do baço tanto no campo experimental como no campo clínico 7,8. Em ambos os tipos de estudo, apesar da maioria dos autores concluírem que a esplenectomia acarreta uma diminuição da defesa imunológica, ainda existem divergências de resultados e, portanto, necessidade de mais estudos ${ }^{9}$. A OPSI (overwhelming post-splenectomy infection ou septicemia grave pós-esplenectomia) é uma situação clínica observada por vários autores ${ }^{10}$.

Nesta pesquisa, o rato foi o animal escolhido por apresentar facilidade de manuseio e, principalmente, por apresentar flora bacteriana intestinal mista semelhante à do homem. Optou-se por induzir a peritonite através de lesão traumática do cólon pois, desta forma, a situação vivenciada no atendimento emergencial de trauma abdominal com comprometimento esplênico associado ao risco de peritonite por contaminação da cavidade com espécies bacterianas aeróbicas da flora entérica pôde ser mais bem simulada. Não foi encontrado na literatura relato de outro experimento que tenha usado este procedimento. Em relação aos resultados de mortalidade, Weistein et al. (1975)", num estudo com ratos, em que a indução da peritonite se deu por inoculação de fezes do próprio animal na cavidade abdominal, observaram 37\% de óbitos e abscessos desenvolvidos em todos os animais sobreviventes (63\%). Neste estudo, a mortalidade obtida no Grupo A, foi semelhante (35\%), porém, um percentual menor de animais desenvolveu abscessos (45\%). Moustoukas et al. (1984) 12 induziram peritonite em ratos através de inoculação de fezes humanas na cavidade abdominal e observaram o índice de mortalidade de $70 \%$ no grupo que foi submetido só à laparotomia e mortalidade de $95 \%$ no grupo no qual foi realizada a esplenectomia, sugerindo que a peritonite por inoculação de fezes humanas em ratos tem alto potencial de virulência.

Os resultados da pesquisa dos agentes bacterianos aeróbicos presentes no lavado colônico utilizado como inóculo revelaram semelhança de espécies entre os três grupos de animais. Tal resultado era esperado, já que todos os animais tinham peso e idade semelhantes e foram submetidos ao mesmo processo de contaminação da cavidade peritoneal ${ }^{13}$, fato que torna os grupos comparáveis considerando o objetivo do trabalho.

Pelo estudo microscópico, foi evidenciado na fase inicial do experimento que, durante as primeiras 96 horas de pós-operatório, houve reação inflamatória menos intensa no grupo de animais esplenectomizados do que nos animais que tiveram o baço preservado. Edemas da sub-mucosa foram observados tanto no Grupo $\mathrm{A}_{2}$ como no Grupo B, porém, de forma discreta nos animais esplenectomizados e acentuada nos animais normais. Ambos os grupos apresentaram evolução favorável entre os períodos de 48hs e $96 \mathrm{hs}$, pois nesta última avaliação os animais do Grupo B já não tinham edemas e os do Grupo $A_{2}$ eram discretos. Estes achados confirmam os resultados de Franco et al. (1986) 14, que observaram em estudo experimental em ratos a diminuição da resposta inflamatória aguda quando da ausência do baço. Os autores comentam que a esplenectomia diminui a população de plaquetas jovens que têm maior capacidade funcional que aqueles presentes no sangue periférico, prejudicando assim a habilidade do organismo de responder ao trauma. $\mathrm{Na}$ fase tardia ( $12^{\circ}$. dia), quando foram estudados somente os animais que sobreviveram à peritonite, não foram evidenciadas diferenças microscópicas importantes entre os grupos.

No que diz respeito a abscessos, os locais mais comuns de formação foram a região de sutura do cólon, a parede abdominal, inter-alças e sub-hepático. Não foram encontradas diferenças significativas entre os grupos em relação à presença de abscessos na parede ou intra-abdominais e em relação a alterações no tórax. Quanto ao líquido na cavidade abdominal, no Grupo $\mathrm{A}_{2}$ há menos presença do que no Grupo
B. Os grupos diferem significativamente quando comparados em relação à ocorrência de peritonite difusa e distensão de alças. Como principal resultado deste estudo, constatou-se alta significância na comparação da mortalidade do Grupo A (0\%) e do Grupo B (80\%), indicando a diminuição da resistência à peritonite dos animais que foram submetidos à esplenectomia. Diferença significante também foi obtida quando a mortalidade do Grupo B foi comparada à do Grupo A (35\%). Tais resultados levam à conclusão de que os animais esplectomizados não foram capazes de superar o processo de peritonite ocasionada pela contaminação e que a ausência do baço leva mais a óbito do que a ausência de sutura na lesão. Nesses animais, o baço exerce fundamental papel na fabocitose e clareamento de partículas. Sugere-se, com base nos resultados deste estudo que, nos casos de trauma abdominal em que haja lesões associadas de cólon e baço ou qualquer outra situação de contaminação da cavidade abdominal, sejam feitas todas as tentativas de preservação do baço.

\section{Conflito de interesse: não há.}

\section{SUMMARY \\ EFFECTS OF SPLENECTOMY ON PERITONITIS PRODUCED BY A COLONIC INJURY: STUDY IN RATS}

BACKGROUND. Study the effects of splenectomy on the intra-abdominal infection by bowel flora, consequent to a colonic injury in Wistar rats.

Methods. We used 64 animals, 20 for Group $A_{1}$ (normal with colon lesion left open), 22 for Group $\mathrm{A}_{2}$ (normal with colon lesion sutured) and 22 for Group B (spleen removed). The animals were submitted to a laparatomy through a midline abdominal incision and peritonitis was induced by a colonic lesion in the colon previously distended with $2 \mathrm{ml}$ of saline introduced in the rectum. Bacteriological studies of the abdominal wash obtained with a sterilized swab and microscopic studies of samples of the segment of the sutured colon obtained at 48hrs, $96 \mathrm{hrs}$ and on the 12 post op day, were made in each group. All rats were submitted to an autopsy on the day of death or on the I2th post op day when the survivors were sacrificed.

RESULTS. Similar bacteria were found in the three groups. E. coli (100\%); Enterococcus fecalis (97\%); Klebsiela pneumoniae (70\%); 
Citrobacter freundi (70\%) and Enterobacter aglomerans (63\%). In the first 96 hours the rats without spleen had a lesser inflammatory reaction when compared to the group with spleen. The leading cause of death was generalized peritonitis in the first 96 hours. There was a significant statistical difference in the mortality rate between Group B (80\%), Group $\mathrm{A}_{2}$ (no mortality) and Group A, (35\%). CONCLUsion. There was a significant statistical difference in the mortality rate caused by peritonitis between the groups with splenectomy when compared to the group with no splenectomy. [Rev Assoc Med Bras 2004; 50(3): 268-7I]

KeY wORDs: Splenectomy. Colon. Peritonitis. Mortality.

\section{REFERÊNCIAS}

I. Leung LE, Szal GJ, Drachman RH. Increased suscepitibility of splenectomized rats to infection with Diplococcus pneumoniae. J Infect Dis 1972; 126:507-13.
2. Schulkind ML, Ellis EF, Smith RT. Effect of antibody upon clearence of I - labelled pneumococci by the spleen and liver. Pediatr Res 1967; I: | 78- | 84.

3. Constantopoulos A, Najjar VA, Wish JB, Necheles TH, Stolbach LL. Defective phagocytosis due to tuftsin deficiency in splenectomized subjects. Am J Dis Child 1973; 125:663-5.

4. Toutouzas KG, Velmahos GC, Kaminski A, Chan L, Demetriades D. Leukocytosis after posttraumatic splenectomy: a physiologic event or sign of sepsis? Arch Surg 2002, 137:924-8.

5. Wolf HM, Eibl MM, Georgi E, Samstag A, Spatz $M$, Uranüs $S$, et al. Long-term decrease of CD4+CD45RA+T cells and impaired primary immune response after post-traumatic splenectomy. $\mathrm{Br} J$ Haematol 1999; 107:55-68.

6. Traetow WD, Fabri PJ, Carey LC. Changing indications for splenectomy. Arch Surg 1980; II5: 447-5I.

7. King H, Schumacker HB. Splenic studies. I. Suscepitibility to infection after splenectomy performed in infancy. Ann Surg 1952; 136:239-42.

8. Sherman R. Perspectives in management of trauma to the spleen. 1979 Presidential
Adress, American Association for the Sugery of Trauma. J Trauma 1980; 20: I - 13.

9. Singer DB. Post-splenectomy sepsis. Perspect Pediatr Pathol 1973; I:285-3 | |

10. Hansen K, Singer DB. Asplenic-hyposplenic overwhelming sepsis: postsplenectomy sepsis revisited. Pediatr Dev Pathol 200 I; 4:05-2I.

11. Weisntein WM, Onderdonk AB, Bartellet JG, Louie TJ, Gorbach SL. Antimicrobial therapy of experimental intraabdominal sepsis. J Infect Dis 1975; 132:282-6.

12. Moustoukas N, Browder W, Gleason C, Di Luzio N, Nichols RL. Adverse effect of splenectomy in experimental peritonits. J Surg Res 1985; 38:574-81.

13. Altemeier WA, Culbertson WR, Fullen WD, Shook CD. Intra-abdominal abscesses. Am J Surg 1973; 125:70-9.

14. Franco CD, Spillert CR, Donohoe MJ, Lazaro EJ. Effect of splenectomy in acute inflammation. Am Surg 1986; 52:337-9.

Artigo recebido: 18/09/2003 Aceito para publicação: 02/03/2004 